\title{
Heritability of size but not symmetry in a sexually selected trait chosen by female earwigs
}

\author{
J OSEPH L. TOMKINS*† \& LEIGH W. SIMMONS: \\ $\dagger$ School of Biological Sciences, The University of Liverpool, P.O. Box 147, Liverpool L69 3BX, U.K. and †Department \\ of Zoology, The University of Western Australia, Nedlands 6009, Western Australia
}

\begin{abstract}
The heritability of fitness-related traits remains an area of contention in evolutionary biology: despite theoretical arguments for little additive genetic variance in fitness-related traits, significant heritabilities in secondary sexual traits are an increasingly reported phenomenon. Some evidence suggests that fluctuating asymmetry (FA) in secondary sexual traits may reflect the genetic quality of the trait bearer. Consequently, females in search of 'good genes' should pay attention to ornament symmetry. If FA does reflect genetic quality which females can assess, an additive genetic component would be expected. Using sib analysis, we found that the length of the sexually selected forceps of male European earwigs (Forficula auricularia) have significant levels of additive genetic variance. However, using both sib analysis and an estimate derived from the genetic and phenotypic correlations of the left and right sides, we found no evidence for additive genetic variance in forceps FA. These results thus provide evidence that female preferences for exaggerated secondary sexual traits can influence trait expression in offspring.
\end{abstract}

Keywords: developmental instability, heritability, sexual selection.

\section{Introduction}

Where females derive no direct benefit from mating with particular males, mate choice is thought to have evolved through the genetic benefit derived by the females' offspring (Andersson, 1994). Indeed, a growing body of empirical evidence suggests that the characteristics of males that females are choosing reflect genetic quality (Andersson, 1994). Implicit in such a mechanism is the heritability of the beneficial characteristics that are subject to female choice (Kirkpatrick \& Ryan, 1991). The heritability of fitness is, however, an area of some controversy (Burt, 1995). Traits associated with fitness are likely to be subject to strong directional selection, so that alleles coding for their expression are expected to spread rapidly throughout a population, thereby reducing additive genetic variance (Falconer \& Mackay, 1996). A number of studies have shown that some sexually selected traits that are associated with increased fitness do have high and significant heritabilities (Pomiankowski \& Møller, 1995).

*Correspondence and present address: Department of Zoology, the University of Western Australia, Nedlands 6009, Western Australia. E-mail: jtomkins@cyllene.uwa.edu.au
Furthermore, recent studies have suggested that in secondary sexual traits the proportion of total phenotypic variance that is additive genetic may be greater than for traits subject to stabilizing selection (Pomiankowski \& Møller, 1995; Day et al., 1996). The mechanisms by which heritability might be maintained in these traits have been discussed by a number of authors (Pomiankowski \& Møller, 1995; Rowe \& Houle, 1996).

Fluctuating asymmetry (FA) in secondary sexual traits is thought to reflect reliably the developmental stability, and hence the genetic quality, of individual males within a population (Møller, 1990). Møller (1990) has proposed that by paying attention to asymmetries in the secondary sexual traits of males, females might be able to bias their mate choice decisions towards males with good genes. In support of this hypothesis, female preferences have been found to correlate with aspects of male symmetry in some taxa (Møller \& Thornhill, 1998). However, other studies have shown that symmetry does not influence female choice (Jennions, 1998; Tomkins \& Simmons, 1998).

Of particular importance to the understanding of the role of FA in sexual selection is its heritability: if 
FA does reflect genetic quality, the so-called 'good genes' that are associated with developmental stability should be carried to offspring and FA should be heritable. Alternatively, low heritability of FA would suggest that FA in secondary sexual traits does not have an additive genetic component and is therefore a poor mate choice cue for females in search of 'good genes'.

There have been a number of significant heritabilities reported for FA in the context of sexual selection. Thornhill \& Sauer (1992) report high heritabilities for wing asymmetries in the scorpion fly Panorpa japonica and Møller (1994) reports significant heritability of tail streamer asymmetry in the barn swallow Hirundo rustica, perhaps giving the reason behind the finding that females in these two species prefer symmetrical males. Møller (1996) has also reported significant heritability of floral FA in Epilobium angustifolium, a species in which floral symmetry is associated with more frequent visits by the principal pollinator Bombus terrestris (Møller, 1995). Contrary to these significant heritabilities, Eggert \& Sakaluk (1994) found no additive genetic variance in two measures of asymmetry in the sexually selected wings of the decorated cricket Gryllodes sigillatus. Controversy currently rages over whether developmental stability is in general a heritable trait. Møller \& Thornhill (1997) conducted a meta-analysis of 34 studies of 17 species and found that the average weighted effect size for heritability was significantly different from zero. However, this analysis has been strongly criticized by a number of authors, who claim that Møller \& Thornhill's analysis is inappropriate or in some other way flawed (see commentaries that follow Møller \& Thornhill (1997) in the same issue).

In the European earwig, Forficula auricularia, forceps are sexually dimorphic. Male forceps are secondary sexual traits and are under directional selection from female choice (Tomkins \& Simmons, 1998). However, although females prefer longer forceps they do not show any preference for more symmetrical forceps (Tomkins \& Simmons, 1998). This female disregard for the symmetry of male forceps may arise if forceps FA does not reliably indicate male quality (Tomkins \& Simmons, 1995, 1996, 1998). The extent to which male body size, forceps size and forceps asymmetry are heritable is the subject of this paper.

\section{Materials and methods}

Approximately 30 male and 30 female earwigs were collected from Umbria in Italy in 1994. These earwigs were maintained in a population cage and allowed to mate. Offspring from the field-collected adults were reared in pairs in $50 \mathrm{~mm}$ diameter Petri dishes and were provided ad libitum with a pollen/ fish flake mix and water. The $F_{1}$ laboratory-reared earwigs provided the sires for the heritability experiment. The $F_{1}$ had a distribution of forceps lengths and pronotum widths to the left of the field-caught individuals, indicating that they were nutritionally stressed (Fig. 1). Increased stress in laboratoryreared generations will promote the expression of subtle asymmetries that might otherwise be masked in earwigs reared under ideal conditions. The pronotum widths and left and right forceps lengths of adult males and females were measured under a binocular microscope, and forceps FA was calculated. Thirty sires were chosen from the $F_{1}$ population (Fig. 1) to cover the range of available pronotum widths and to represent the extremes of forceps length for each pronotum width; this procedure increases the precision of heritability estimates (Falconer \& Mackay, 1996). Sires were predominantly from the brachylabic morph (forceps $<6 \mathrm{~mm}$ ), because of rarity of macrolabic males (Fig. 1). Each male was paired in succession with four virgin females. The four females were siblings, but were unrelated to the male, or the females paired to any other male.

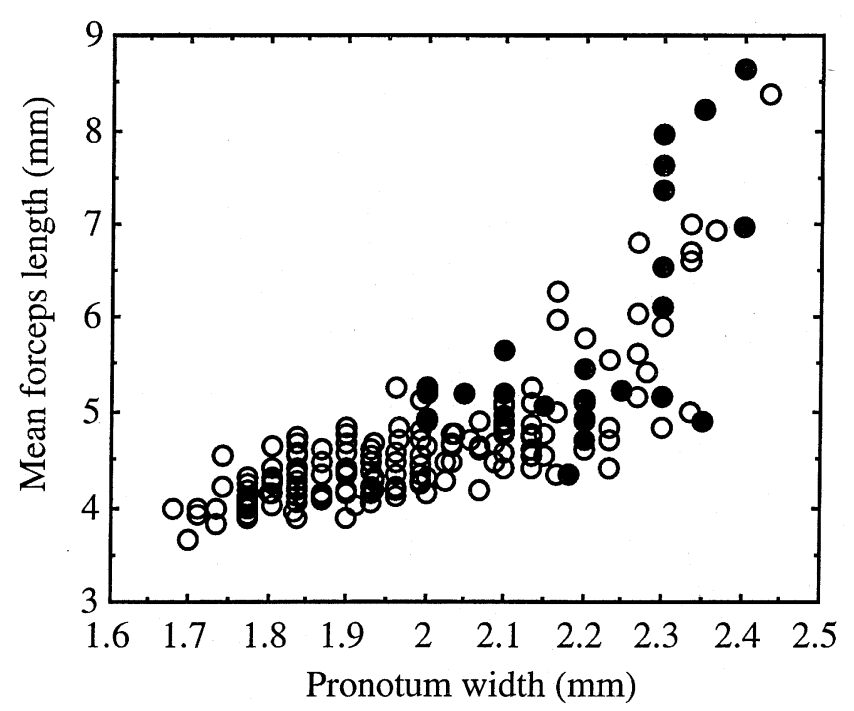

Fig. 1 Forceps length and pronotum width scatter of the field-collected population (filled circles) and the laboratory-reared $\mathrm{F}_{1}$ (sire) population (open circles) of Forficula auricularia; earwigs with forceps larger than $6 \mathrm{~mm}$ are macrolabic (see Tomkins \& Simmons, 1996, for methods of discriminating between morphs).

(C) The Genetical Society of Great Britain, Heredity, 82, 151-157. 
Nesting chambers were made by half filling $10 \mathrm{~cm}$ diameter flowerpots with moist 50:50 sand and potting compost. A depression $1 \mathrm{~cm}$ deep and $2 \times 1 \mathrm{~cm}$ wide was made in the centre of the compacted soil and a blacked-out Petri dish lid was placed over the depression. A $10 \mathrm{~cm}$ diameter Petri dish lid or base was placed inside the flowerpot neck to prevent the earwigs from escaping.

To ensure that each female had been mated by the male, females were kept singly with the male in a Petri dish for one week each. Subsequently males were rotated weekly among their females to ensure that females had freshly inseminated sperm at the time of fertilization. The flowerpots containing earwigs were placed in an unheated greenhouse over the winter. Each pot was moistened weekly and checked for eggs. Pollen granules were provided in warm weather when the earwigs were active.

Flowerpots containing females with eggs were placed in an insectary at $15^{\circ} \mathrm{C}$ with a $12: 12$ light:dark cycle. Flowerpots in the insectary were kept moist and after 20 days were checked daily for hatched nymphs.

First-instar nymphs were tended by their mother for the first week after hatching and then transferred to $50 \mathrm{~mm}$ diameter Petri dishes. Eight nymphs were placed into each Petri dish, and were provided with fish flake and water ad libitum. These conditions lead to $34 \%$ mortality and a distribution of forceps lengths and pronotum widths to the left of the fieldcollected individuals, indicating the relatively high levels of stress in the offspring population; such levels are expected to promote the expression of developmental instability. Pronotum and left and right forceps lengths of adult males were measured after adult eclosion.

The forceps of $F$. auricularia are known to show fluctuating asymmetry (Tomkins \& Simmons, 1995, 1996). Fluctuating asymmetry was tested for in the largest sample available, which was for the offspring from the experiment. The mean right-minus-left asymmetry in the forceps of the offspring did not differ from zero (mean $=0.001 \pm 0.005, t_{305}=0.244$, NS) and although there was significant kurtosis (1.844 $\pm 0.28, \quad n=306, \quad t=6.586, \quad P<0.0001) \quad$ the distribution of asymmetries was not significantly skewed $(0.215 \pm 0.14, n=306, t=1.53$, NS). The repeatability of forceps length asymmetry was calculated from the independent measurements of two observers (Tomkins \& Simmons, 1995). Measurement of forceps asymmetry is highly and significantly repeatable in this species $(R=0.92 \pm 0.022$, repeated measures ANOVA, $F_{43,44}=23.46, \quad P<0.0001$; Tomkins \& Simmons,
1995). Measurement error, calculated as the proportion of total variation in FA that is found in the within-individual repeated measures, was also low $(8.16 \%)$. The absolute $\mathrm{R}-\mathrm{L}$ values of FA were used in the parent-offspring regression and sib analysis.

\section{Results}

\section{Sib analysis}

The heritabilities and variance components for the pronotum width and forceps traits in this experiment were estimated using sib analysis. Unequal numbers of offspring and of dams per sire were controlled for by using mean values (Falconer \& Mackay, 1996). The sib analysis revealed significant variance attributable to dams but not sires in pronotum width. For mean forceps length and forceps FA there were no significant dam effects (Table 1). Following the procedures outlined in Underwood (1997), the sums of squares of dams within sires and of progeny were pooled and used in a more powerful post hoc test. Using pooled mean squares revealed significant variance attributable to sires in forceps length $\left(F_{21,210}=2.29, P=0.0016\right)$ but no significant variance attributable to sires in FA $\left(F_{21,210}=0.409\right.$, NS $)$. The sib analysis was conducted using the JMP statistical software. We used the power analysis procedures to determine the power with which we could reject the notion of significant additive genetic variance in forceps FA. The recent meta-analysis of Møller \& Thornhill (1997) found the mean effect size of FA heritability to be 0.19 .

Table 1 Sib analysis: nested analysis of variance of pronotum width, forceps length and forceps FA in earwigs

\begin{tabular}{lrccl}
\hline Source & d.f. & SS & MS & $F$-ratio \\
\hline Pronotum width & & & & \\
Fathers & 21 & 0.315 & 0.01503 & 1.37 \\
Mothers (within fathers) & 24 & 0.266 & 0.01107 & $2.31^{* *}$ \\
Within progenies & 187 & 0.896 & 0.00479 & \\
Forceps length & & & & \\
Fathers & 21 & 14.405 & 0.68594 & 1.59 \\
Mothers (within fathers) & 24 & 10.387 & 0.43283 & 1.53 \\
Within progenies & 187 & 52.892 & 0.28384 & \\
Forceps FA & & & & \\
Fathers & 21 & 0.224 & 0.01069 & 0.53 \\
Mothers (within fathers) & 24 & 0.483 & 0.02012 & 0.80 \\
Within progenies & 187 & 5.038 & 0.02694 & \\
\hline
\end{tabular}

$* * P<0.01$; d.f. calculated from Falconer \& Mackay $(1996)$; sires $=22$, mean dams per sire $=2.09$, mean offspring per dam $=5.06$. 
The power of our analysis to detect an effect size as large as 0.19 was 1.0 , justifying our rejection of the null hypothesis of genetic variance in forceps FA expected from Møller and Thornhill's analysis. Further, at the critical power level of 0.80 , our analysis could reliably detect effect sizes $\geq 0.051$, well below the mean effect size from the metaanalysis.

The observational variances were derived from the sib analysis, and heritability estimates were calculated from those variances (Table 2) (Falconer \& Mackay, 1996). Note that heritability estimates, their standard errors (Roff, 1997) and causal components of variance (Table 3 ) were corrected for the experimental design of paternal half-sibs plus single first-cousins (dams full-sibs) (Eisen, 1967). For pronotum width, the variance attributable to dams was greater than that to sires, which suggests that there is either a dominance effect or an effect of common environment (Falconer \& Mackay, 1996). The effect of common environment is more likely, because all of the offspring from a single dam were reared together in only one or two Petri dishes. Moreover, the parental care provided by the female in the first week after hatching may have increased this effect. The causal components of variance (Table 3) have been calculated assuming that dominance variance $=0$ (Falconer \& Mackay, 1996): the breeding design adopted reduces dominance effects by pairing sib females with a single male (Eisen, 1967; Becker, 1984). The effect of common environment $\left(V_{\mathrm{EC}}\right)$, which is composed of both maternal and dominance variance, is low for both forceps length and asymmetry (Table 3 ). However, $V_{\mathrm{EC}}$ accounts for a large proportion of the total variance in pronotum width (Table 3 ) and the estimated heritability for dam pronotum width may therefore be inflated (Falconer \& Mackay, 1996).

From the half-sib analysis we have established that sires contribute significantly to the variance in their offspring's forceps length. Consequently, because $h^{2}=V_{\mathrm{A}} / V_{\mathrm{P}}$, additive genetic variance in forceps length gives rise to the heritabilities for forceps length (Table 2). The heritability of pronotum width may be elevated because of $V_{\mathrm{EC}}$. However, because the variance in forceps FA is entirely caused by the variance within sibs (i.e. variation which is not because of relatedness or the common environment), FA appears to arise at random and forceps FA is not heritable (Tables 2 and 4). The coefficient of additive genetic variance $\left(C V_{\mathrm{A}}\right)$, has been proposed as an appropriate measure for comparing the additive genetic variance

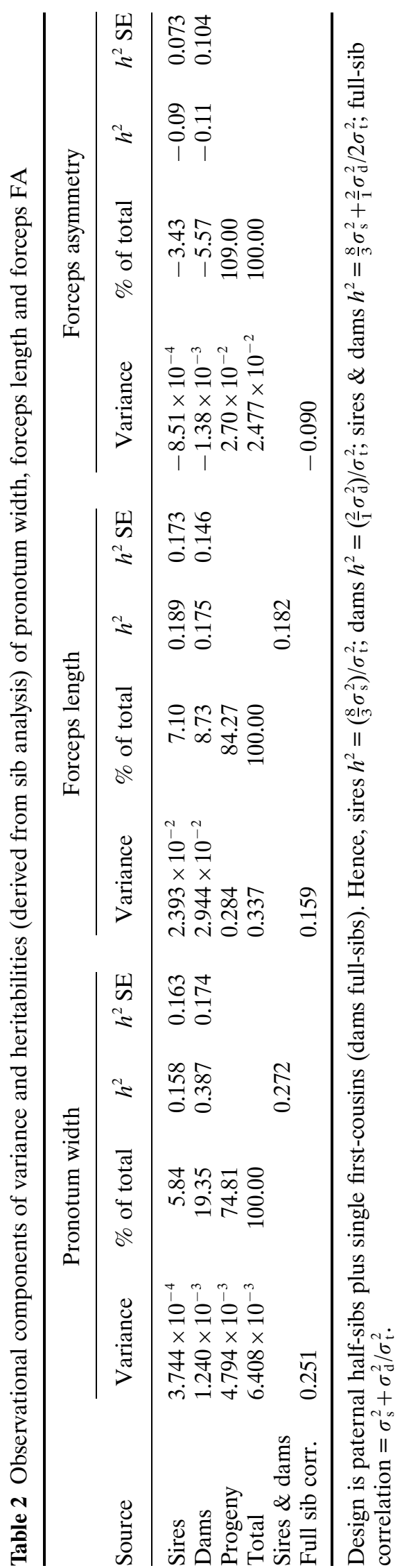

(c) The Genetical Society of Great Britain, Heredity, 82, 151-157. 
Table 3 Causal components of variance (derived from sib-analysis) for pronotum width, forceps length and forceps FA

\begin{tabular}{|c|c|c|c|c|c|c|}
\hline \multirow{2}{*}{$\frac{\text { Source }}{V_{\mathrm{A}}}$} & \multicolumn{2}{|c|}{ Pronotum width } & \multicolumn{2}{|c|}{ Forceps length } & \multicolumn{2}{|c|}{ Forceps asymmetry } \\
\hline & $9.984 \times 10^{-4}$ & $15.58 \%$ & $6.382 \times 10^{-2}$ & $18.93 \%$ & $-2.269 \times 10^{-3}$ & $-9.16 \%$ \\
\hline$V_{\mathrm{EC}}$ & $1.193 \times 10^{-3}$ & $18.61 \%$ & $2.146 \times 10^{-2}$ & $6.36 \%$ & $-1.273 \times 10^{-3}$ & $-5.14 \%$ \\
\hline$V_{\mathrm{EW}}$ & $4.295 \times 10^{-3}$ & $67.02 \%$ & 0.252 & $74.77 \%$ & $2.813 \times 10^{-2}$ & $113.56 \%$ \\
\hline$V_{\mathrm{P}}$ & $6.408 \times 10^{-3}$ & $100 \%$ & 0.337 & $100 \%$ & $2.477 \times 10^{-2}$ & $100 \%$ \\
\hline
\end{tabular}

Design is paternal-half-sibs plus single first-cousins (dams full-sibs). Hence, $V_{\mathrm{P}}=\sigma_{\mathrm{t}}^{2} ; V_{\mathrm{A}}=\frac{8}{3} \sigma_{\mathrm{s}}^{2} ; V_{\mathrm{EC}}=\sigma_{\mathrm{d}}^{2}-\frac{1}{8} \sigma_{\mathrm{s}}^{2}$;

$V_{\mathrm{EW}}=\sigma^{2}-\frac{4}{3} \sigma_{\mathrm{s}}^{2}$.

between taxa (Houle, 1992); for pronotum width $C V_{\mathrm{A}}=1.557$ (mean pronotum width $=2.028 \mathrm{~mm}$ ) and for forceps $C V_{\mathrm{A}}=5.075$ (mean forceps length $=4.978 \mathrm{~mm}) . C V_{\mathrm{A}}$ was not calculated for forceps $\mathrm{FA}$ because the additive genetic variance was negative.

$\mathrm{h}_{\mathrm{FA}}^{2}$ and genetic and phenotypic correlations between left and right sides

In addition to the estimation of the heritability of FA by sib analysis, a second method was employed. This method is specific to the estimation of FA heritabilities and uses the additive genetic correlation and phenotypic correlations between left and right sides (Roff, 1997). Essentially, the greater the genetic correlation $\left(r_{\mathrm{A}}\right)$ between the lengths of left and right sides of a trait, the smaller will be the heritability of FA (Roff, 1997). Following the procedures set out in Roff (1997), the heritability of FA was estimated to be $h_{\mathrm{FA}}^{2}=-0.145\left(r_{\mathrm{A} \text { (sires and- }}\right.$ dams) $=1.0287 ; r_{\mathrm{P}}=0.9648 ; h^{2}$ (left and right) $\left.=0.177\right)$.

\section{Parent-offspring regression}

The design of this heritability experiment (parental full-sibs plus single first-cousins (dams full-sibs), precludes the calculation of heritability from parentoffspring regression. Nevertheless, the phenotypic relationships between sires and the mean offspring values (weighted according to Kempthorne \& Tandon, 1953) were significant for both forceps length $\quad\left(F_{1,20}=6.19, \quad P<0.05, \quad b=0.314 \pm 0.13\right)$ (Fig. 2) and pronotum width $\left(F_{1,20}=3.37, P=0.08\right.$, $b=0.128 \pm 0.07)$. There was no relation between absolute $\mathrm{R}-\mathrm{L}$ forceps $\mathrm{FA}$ in sires and in their sons $\left(F_{1,20}=0.023, \mathrm{NS}, b=0.013 \pm 0.17\right)$. Our sib analysis shows that the relation between forceps length in fathers and sons is generated in part by additive genetic variance.

\section{Discussion}

Several factors may have influenced the heritability estimates reported here. Laboratory studies have been considered to overestimate the natural heritabilities from the field, because of the increased environmental variance in the field and the novel environment of the laboratory (Falconer \& Mackay, 1996; Weigensberg \& Roff, 1996). However, a recent comparative study of laboratory and field heritabilities concluded that laboratory estimates do provide a realistic estimate of the magnitude and significance of heritabilities in the field (Weigensberg \& Roff, 1996). The offspring were not reared at the same density as their fathers, nevertheless density has been found not to affect pronotum width, forceps length, or FA in other studies of this species (J.L.T., unpubl. data) Although there was a strong effect of common environment, which appears to have increased the heritability estimate of pronotum width attributable to dams, the common

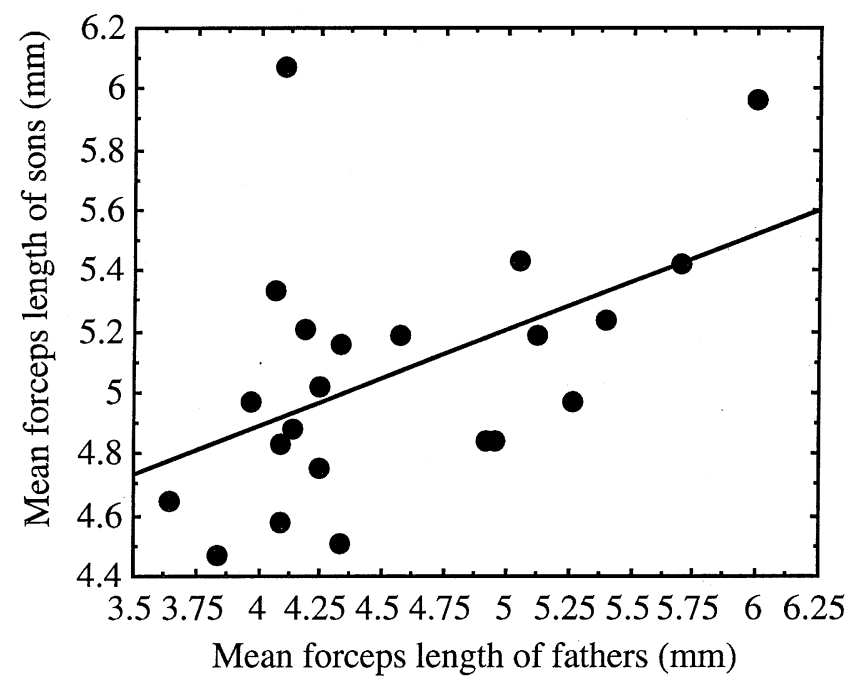

Fig. 2 Regression of mean weighted forceps length of offspring on sire forceps length. 
environmental effect on forceps length was small. The variance in forceps length (and heritability) attributable to dams is therefore likely to be a robust estimate.

The heritabilities for forceps length are of a similar magnitude to those reported elsewhere in the literature for secondary sexual traits (Pomiankowski $\&$ Møller, 1995). Indeed, contrary to the theoretical expectation for low additive genetic variance of fitness characters (Fisher, 1958), Pomiankowski \& Møller (1995) have found from the literature that secondary sexual traits have significantly higher coefficients of additive genetic variation $\left(C V_{\mathrm{A}}\right)$ than nonsexually selected traits. Day et al. (1996) recently found empirical support for Pomiankowski \& Møller's (1995) study, demonstrating that in the seaweed fly Coelopa frigida the $C V_{\mathrm{A}}$ of wing length, a sexually selected trait, was greater in males than in females. Our study shows the same pattern, with a higher $C V_{\mathrm{A}}$ for the sexually selected forceps than for pronotum width. Nevertheless the validity of such comparisons rests on the assumption that different traits scale equally with body size (Roff, 1997). This is almost certainly not the case for sexually and nonsexually selected traits (Simmons \& Tomkins, 1996, and references therein).

The widespread evidence for genetic variation in fitness-related traits has generated a number of hypotheses for its maintenance (Pomiankowski \& Møller, 1995; Rowe \& Houle, 1996). In earwigs, mutation or other phenomena, such as a negative pleiotropy associated with the production of large forceps, may maintain genetic variance. For example, Arnqvist (1994) has demonstrated a sizerelated cost to the production of sexually selected genital claspers in the water strider (Gerris odontogaster): male water striders with large genital claspers took longer to eclose during the final moult than males with smaller claspers, and at high densities, in particular, moult duration correlated positively with the probability of being cannibalized.

Pomiankowski \& Møller (1995) suggested that if fitness increases at a greater than linear rate with respect to trait exaggeration, genetic variance might be maintained by the increased number of loci or increased contribution of loci that the favoured increase in phenotypic variation would produce. This model has been criticized for its reliance upon net directional selection on secondary sexual traits which may not exist when traits have reached their naturally selected optima (Rowe \& Houle, 1996). Rowe $\&$ Houle (1996) proposed that the source of additive genetic variation is the additive genetic variation of condition. Their assumptions were only that condition-dependence of traits evolves and that many loci affect condition, the result of which was that condition-dependent traits 'capture' some of the genetic variance of condition (Rowe \& Houle, 1996). Whether the maintenance of additive genetic variance in secondary sexual traits such as earwig forceps results from local phenomena such as migration, species-specific effects such as negative pleiotropy, or from an underlying genetic association between trait and condition, remains to be tested.

The additive genetic component of FA in earwig forceps appears to be very low, suggesting that forceps FA may not reflect male genotypic quality. Further support for the latter conclusion comes from the lack of negative relationships between forceps size and symmetry in the Dermaptera (Tomkins \& Simmons, 1995), and the equally high levels of asymmetry in males of both morphs (Tomkins \& Simmons, 1996).

Variation in FA that is indicative of male quality might only be expected when populations are reared under conditions that challenge homeostatic mechanisms. Both sire and offspring populations were stressed, as indicated by the reduced size of forceps and $34 \%$ mortality in nymphs. Thus any heritable variation in developmental stability should have been readily observable. A lack of additive genetic variation in forceps FA would perhaps be more surprising if female earwigs actively chose males on the basis of their forceps FA. However, females choose males with long forceps regardless of their symmetry (Tomkins \& Simmons, 1998).

The recent meta-analysis by Møller \& Thornhill (1997), stimulated much debate concerning the general heritability of developmental instability (see commentaries that follow Møller \& Thornhill (1997) in the same issue). Here we cannot draw conclusions regarding the heritability of overall developmental stability in earwigs. Rather, we are concerned with the specific hypothesis that heritability of FA in a secondary sexual trait can provide indirect benefits to offspring via female choice. We find no evidence for this hypothesis. In general, Whitlock (1996) has demonstrated that FA in a single trait should provide a poor indication of any underlying genetic variance in developmental stability.

In conclusion, female $F$. auricularia have been demonstrated to choose males with long or relatively long forceps (Tomkins \& Simmons, 1998). Females that exercise this choice are more likely to have male offspring with large forceps, making their sons preferred as mates and also more successful in 
competition compared to the sons of females that mate at random. Our studies of sexual selection on earwig forceps add to the growing number of taxa in which FA plays no role in sexual signalling.

\section{Acknow ledgements}

We thank Bob Black, Mike Johnson and three anonymous reviewers for their statistical input, and Tom Heyes for help in culturing earwigs. This work was conducted whilst J.L.T. was supported by a BBSRC Ph.D. studentship and written up on a Fellowship from the Royal Society of London. L.W.S. is supported by an ARC Senior Research Fellowship.

\section{References}

Andersson, M. 1994. Sexual Selection. Princeton University Press, Princeton, NJ.

ARNQVist, G. 1994. The cost of male secondary sexual traits: developmental constraints during ontogeny in a sexually dimorphic water strider. Am. Nat., 144, 119-132.

BECKER, w. A. 1984. Manual of Quantitative Genetics. Pullman, Washington, DC.

BURT, A. 1995. The evolution of fitness. Evolution, 49, 1-8.

DAY, T. H., CREAN, C. S., GILBURN, A. S., SHUKER, D. M. AND WILCOCKSON, R. W. 1996. Sexual selection in seaweed flies: genetic variation in male size and its reliability as an indicator in natural populations. Proc. R. Soc. B., 263, 1127-1134.

EGGERT, A. K. AND SAKALuK, s. K. 1994. Fluctuating asymmetry and variation in the size of courtship food gifts in decorated crickets. Am. Nat., 144, 708-716.

EISEN, E. J. 1967. Mating designs for estimating direct and maternal genetic variances and direct-maternal covariances. Can. J. Genet. Cytol., 9, 13-22.

FALCONER, D. S. AND MACKAY, T. F. C. 1996. Introduction to Quantitative Genetics, 4th edn. Longman, New York.

FISHER, R. A. 1958. The Genetical Theory of Natural Selection. Dover, New York.

HOULE, D. 1992. Comparing evolvability and variability of quantitative traits. Genetics, 130, 195-204.

JENNIONS, M. D. 1998. The effect of leg band symmetry on female-male association in zebra finches. Anim. Behav., 55, 61-67.

KEMPTHORNE, O. AND TANDON, O. B. 1953. The estimation of heritability by the regression of offspring on parent. Biometrics, 9, 90-100.
KIRKPATRICK, M. AND RYAN, M. J. 1991. The evolution of mating preferences and the paradox of the lek. Nature, 350, 33-38.

MØLLER, A. P. 1990. Fluctuating asymmetry in male sexual ornaments may reliably reveal male quality. Anim. Behav., 40, 1185-1187.

MøLler, A. P. 1994. Sexual selection in the barn swallow (Hirundo rustica). IV. Patterns of fluctuating asymmetry and selection against asymmetry. Evolution, 48, 658-670.

MØLLER, A. P. 1995. Bumblebee preference for symmetrical flowers. Proc. Natl. Acad. Sci. U.S.A., 92, 2288-2295.

MØLler, A. P. 1996. Developmental stability in flowers, embryo abortion, and developmental selection in plants. Proc. R. Soc. B., 263, 53-56.

MøLlER, A. P. AND THORNHILL, R. 1997. A meta-analysis of the heritability of developmental instability. J. Evol. Biol., 10, 1-16.

MØLLER, A. P. AND THORNHILL, R. 1998. Bilateral symmetry and sexual selection: a meta-analysis. Am. Nat., 151, 174-192.

POMIANKOWSKI, A. AND MøLLER, A. P. 1995. A resolution of the lek paradox. Proc. R. Soc. B, 260, 21-29.

ROFF, D. A. 1997. Evolutionary Quantitative Genetics. Chapman and Hall, New York.

ROWE, L. AND HOUle, D. 1996. The lek paradox and the capture of genetic variance by condition dependent traits. Proc. R. Soc. B, 263, 1415-1421.

SIMMONS, L. W. AND TOMKINS, J. L. 1996. Sexual selection and the allometry of earwig forceps. Evol. Ecol., 10, 97-104.

THORNHILL, R. AND SAUER, P. 1992. Genetic sire effects on the fighting ability of sons and daughters and mating success of sons in a scorpion fly. Anim. Behav., 43, $255-264$.

TOMKINS, J. L. AND SIMMONS, L. W. 1995. Patterns of fluctuating asymmetry in earwig forceps: no evidence for reliable signalling. Proc. R. Soc. B, 259, 89-96.

TOMKINS, J. L. AND SIMMONS, L. W. 1996. Dimorphisms and fluctuating asymmetry in the forceps of male earwigs. J. Evol. Biol., 9, 753-770.

TOMKINS, J. L. AND SIMMONS, L. W. 1998. Female choice and manipulations of forceps size and symmetry in the European earwig Forficula auricularia L. Anim. Behav. 56, 347-356.

Underwood, A. J. 1997. Experiments in Ecology. Cambridge University Press, Cambridge.

WEIGENSBERG, I. AND ROFF, D. 1996. Natural heritabilities: can they be reliably estimated in the laboratory? Evolution, 50, 2149-2151.

whitLOCK, M. 1996. The heritability of fluctuating asymmetry and the genetic control. of developmental stability. Proc. R. Soc. B., 263, 849-854. 